\title{
Characteristics of Students' Cognitive Conflict in Solving a Problem Based on Information Processing Theory
}

\author{
Enditiyas Pratiwi \\ Doctoral Student, Postgraduate of Mathematics Education, State University of \\ Malang, Indonesia
}

\author{
Toto Nusantara, Susiswo Susiswo, Makbul Muksar and Subanji Subanji
}

Postgraduate of Mathematics Education, State University of Malang, Indonesia

\begin{abstract}
The purpose of this study was to describe the characteristics of students' cognitive conflict in solving problems based on information processing theory. This research was descriptive qualitative, and data were collected through direct observation, semi-structured in-depth interviews, and tests. Tests were in the form of story questions with distance material that had been previously studied by students. Participants in this study were grade 6 elementary school students. Out of 32 sixth-grade students, two were selected as participants in the study. The results of the study show that there are two characteristics of students' cognitive conflict in solving problems: error-cognitive conflict-equilibrium-solving the problem and error-cognitive conflict-equilibrium-can't solve the problem. Participants experienced difficulties in accessing information contained in long-term memory, so participants were constrained in connecting the newly received information to their short-term memories. The difficulty in accessing this information resulted in participants' experiencing cognitive conflict. Information was not directly connected between what had been given and what was already available in the cognitive structure. These results indicate that cognitive conflict occurs during information processing if the information received by sensory memory and transferred to short-term memory cannot be directly linked to information in long-term memory.
\end{abstract}

Keywords: education; mathematics; primary school students; cognitive processes; learning processes.

\section{Introduction}

Information processing theory is a cognitive theory of learning that explains the processing, storage, and retrieval of knowledge from the brain (Slavin, 2000). 
This theory explains how a person learns information and can remember it for a long time. The information obtained will be easier to process if the information is well organized. Schunk (2012) argued that organized material will improve memory because the items are systematically connected to one another. The more organized the information presented, the easier it is to remember it. The information that has been received will be encoded, then stored in memory. King (2007) explained that storage includes how information is maintained over time and how information is presented in memory. Memory is used as a place to store information that has been experienced, so memory functions to connect past events with current and future events. This information processing component of memory storage has three stages (Atkinson \& Shiffrin, 1968), namely, (1) sensory memory, (2) short-term memory, and (3) long-term memory.

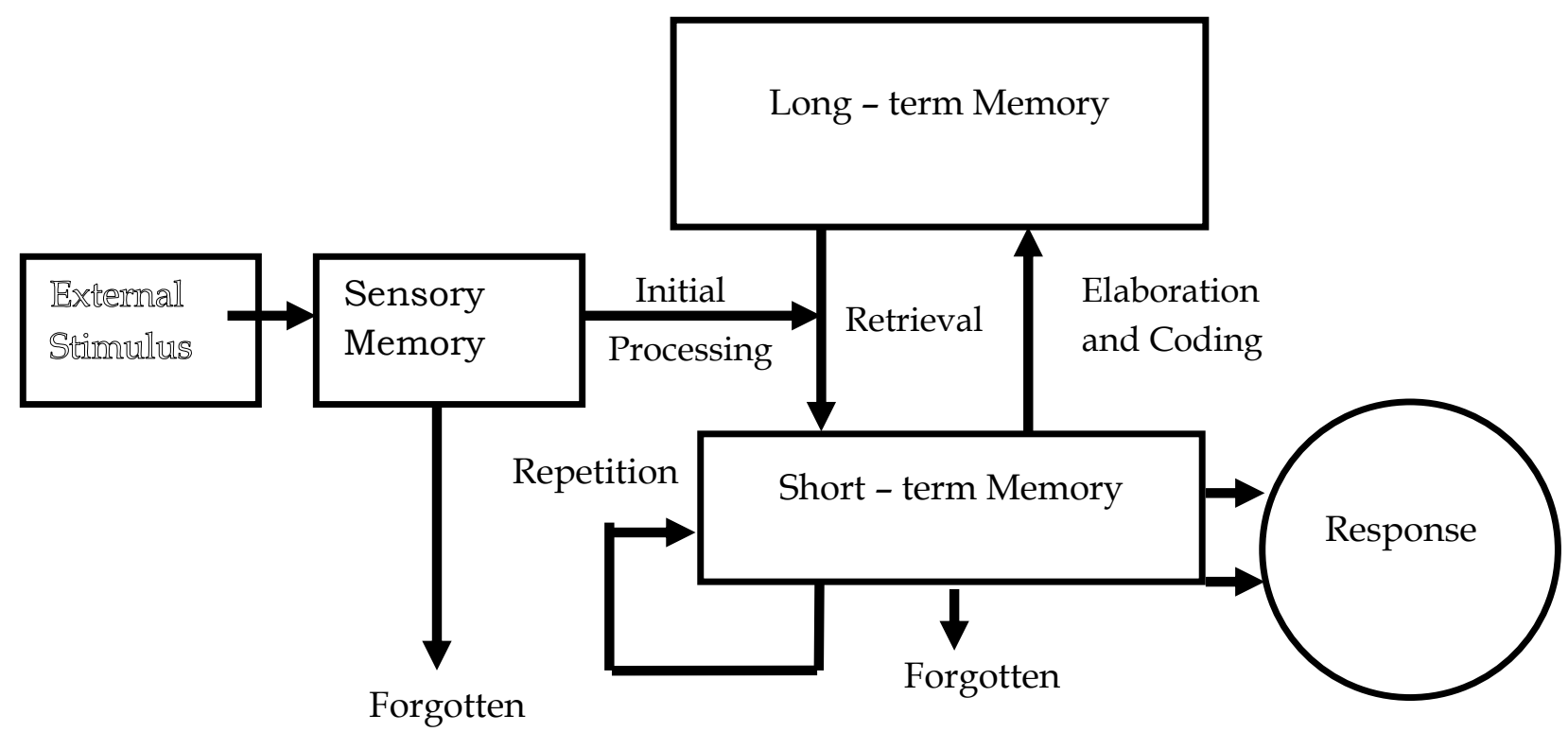

Figure 1. Stage Theory of Information Processing

Information processing begins when an external stimulus concerns one or more of hearing, sight, and touch. Appropriate sensory memory accepts external stimuli and stores them for a while in sensory recordings. Information enters the system via sensory memory but is only stored for a limited period of time. In order to remain in the system, information entered into short-term memory will be combined with information on long-term memory. Adjusting external stimuli that enter to fit existing cognitive structures is an important factor in gaining new knowledge. If external stimulation in the form of new information is not brought to memory in a meaningful way, information will not be stored as memory. In this case there has been a perception (pattern recognition), namely, the process of giving meaning to an external stimulus. Moving quickly to the next processing stage is very important, and sensory memory serves as a portal for all information that is part of a memory. Sensory memory transfers information to short-term memory. Short-term memory is working memory and is related to consciousness or things that are caught by the conscious mind at any given moment. Working memory stores about seven units of information. A 
unit is a meaningful component such as a letter, word, number, or general speech. The capacity and duration of working memory are very limited, so to be maintained in working memory something must be gone over often, because without repetition, the information will disappear after a while. When information is in working memory, the knowledge associated with it in longterm memory, also called permanent memory, will be activated and placed in working memory to be combined with new information. Long-term memory is potentially unlimited in its capacity, so it can accommodate all the information that students already have. The weakness of long-term memory is that it is very difficult to access information stored in it. Students have difficulty accessing information because of imperfect access to information that is alleviated. This condition allows the occurrence of misconceptions or differences in conception between those that have been stored and the information that has just been entered.

In general, there is no conflict between students. Students have their own points of view and are consistent in terms of problem-solving depending on the cognitive structure and in accordance with the rules. If a conflict develops, the first possibility is conflict between students and their environment (with questions, observations, teachers, etc.). The student will consciously or unconsciously deal with the conflict because his actions or reactions are not in accordance with the expectations of his environment, because he does not feel the approval of the teacher, because he gets instructions for a different view of the problem, or because he cannot solve the problem at all (Meissner, 1986).

There are three opinions about the process of the occurrence of a cognitive conflict (Lee \& Kwon, 2001). First, cognitive conflict occurs because of differences in existing conceptions in cognitive structures towards the environment (Piaget, 1985). Second, cognitive conflict occurs because of differences in the existing conceptions of the conceptions that are shielded (Hashweh, 1986). Third, cognitive conflict occurs because of differences in conceptions that protect against the environment (Kwon, 1989).

Mischel (1971, cited in Lee \& Kwon, 2001) defined cognitive conflict as an awareness of momentary imbalances in the schema system. Gredler (1992, cited in Lee \& Kwon, 2001) said that cognitive conflict occurs if children finally become aware of the fact that they have experienced a view of two contradictions about the situation and both are not true. Bodlakova (1998, cited in Lee \& Kwon, 2001) said that cognitive disequilibrium or conflict is caused by the awareness of contradictions in information. Wadsworth (1996, cited in Lee \& Kwon, 2001) said that cognitive conflict is created when one's expectations and predictions based on one's current reasoning are not appropriate, which is imbalance. Lee et al (2003) defined cognitive conflict as a conflict between cognitive structures (i.e., organized structures of knowledge in the brain) and the environment (e.g., an experiment, a demonstration, peer opinions, books, or others), or conflicts between conceptions in cognitive structures.

Understanding in mathematics often takes significant leaps rather than a smooth and stable process. Such a leap in understanding mathematics can cause an individual confusion, making him unable to determine his own difficulties. If this phenomenon is considered to occur as a result of brain activity that is of dynamic flow, then this shows a model that includes a variety of things in the 
aspect of mathematical understanding. When students restructure their mathematical schemes to understand new information, cognitive conflict will occur. This can lead to path-dependent logic, whereby students can provide different answers to the same question depending on their approach to the question. At this stage, students can restructure their ideas and rationalize the exact way they use for short-term benefits but are not suited for the development of long-term schemes (Tall, 1977).

Cognitive conflict is used as a strategy in learning with the aim of increasing understanding, changing concepts, and improving reasoning abilities, besides being used as a means to reconstruct student knowledge (Chow \& Treagust, 2013; Kabaca, Karadag, \& Aktumen, 2011; Limon, 2001; Maharani \& Subanji, 2018; Movshovitz-Hadar, 1990; Tirosh \& Graeber, 1990).

Some of the studies above have not examined the occurrence of cognitive conflict when students solve mathematical problems based on information processing theory. However, there have been studies that link children's cognitive development with the stages of information processing. So, this study will describe the cognitive conflict characterization of students in solving problems based on information processing theory. This study also as an initial study to determine the characteristics of students' cognitive conflict so that it can be used for subsequent research.

\section{Material and Methods}

\subsection{Methodology}

This research was descriptive qualitative because the purpose of this study was to describe the characteristics of students' cognitive conflict in solving problems. The question in this study was how the characteristics of students' cognitive conflict in solving problems were based on information processing theory. Based on the purpose of this study, the researchers will describe the characteristics of students' cognitive conflict in solving problems and where cognitive conflict occurs in the theory of information processing.

\subsection{Participants}

A total of 32 elementary school students in grade 6 were given math story questions about distance material. Of the 32 students who worked on the problem, only two students were used as participants in this study. The reason for choosing these participants was the students' misconceptions when solving mathematical story problems. Such misconceptions have the potential to cause cognitive conflict in students. This is consistent with Wyrasti (2016) and Wyrasti et.al. (2016), who indicated that the construction of analogy errors triggers cognitive conflict.

\subsection{Procedure}

The researchers followed the research procedures described in Figure 2 to work on mathematical story questions with each student in grade 6. After all sixthgrade students had worked on the given problem questions, the researchers analysed the students' answers to determine which students would be participants in the study. Based on the analysis of the students' answers, the 
researchers chose two students to be interviewed semi-in depth. The selection of students as participants in this study was based on their misconceptions when solving story problems. The interviews were conducted to find out in what conditions students experienced cognitive conflict based on information processing. The information processing flow is shown in Figure 1, which starts from the external stimulus that enters sensory memory, then goes to whether the external stimulus that enters the sensory memory will be transferred to the short-term memory or working memory, and how both short-term memory and long-term memory receive external stimuli that have been transferred by sensory memory. The researchers interviewed students to see what conditions in processing this information led to cognitive conflict in students. The researchers directed questions on students' conception of the distance material and paid attention to whether there was a process from short-term memory to long-term memory and vice versa. To find out the condition of students experiencing this cognitive conflict, the researchers delved into the data of semi-structured questions so that it can be known at each stage of information processing whether there is cognitive conflict.

\subsection{Data Analysis}

Data were initially obtained in the form of test results, then analysed to determine whether the students had experienced misconceptions in the process of solving the problems (not focusing on whether their work was right or wrong). Then, the researchers further investigated the students who had experienced misconceptions via interviewing. The interviews explored information related to misconceptions, then whether cognitive conflict had occurred in students and how they had solved problems after experiencing cognitive conflict. The content validity of the test and the guided semistructured interview were addressed by involving various professors across related disciplines. This consultation resulted in a series of substantive changes to the test and semi-structured interview. The process of data analysis in this study follows in Figure 2.

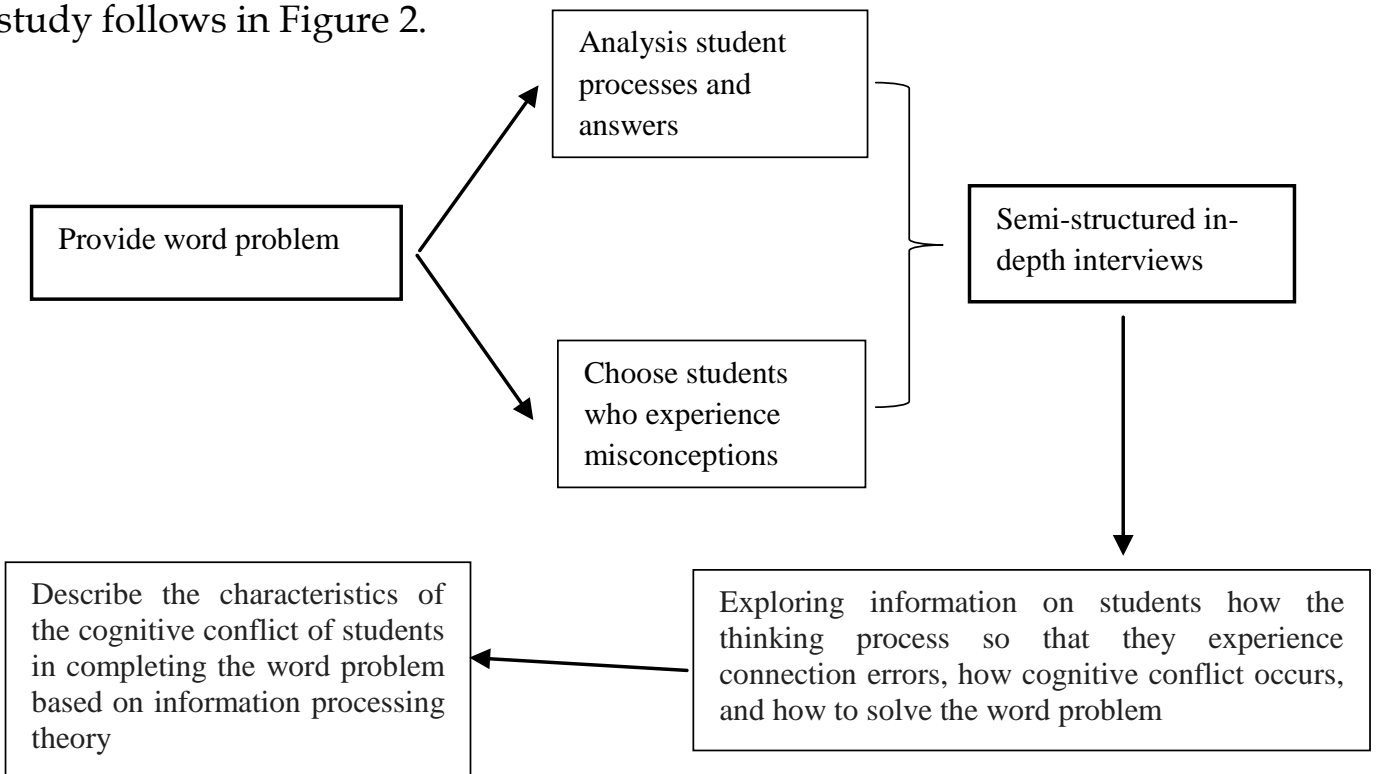

Figure 2. Stages in Determining the Condition of Students Experiencing Cognitive Conflict Based on Information Processing 


\section{Result}

The most important thing in developing children's thinking is equilibrium. Equilibrium is an internal mechanism that regulates a person when faced with external stimuli or challenges. External stimuli enter children's sensory memory and are then transferred to short-term memory. From short-term memory, there is a process to access information in long-term memory and a process to store information from short-term memory. External stimuli can create cognitive conflict in one's thinking.

Two participants were given a story about distance material. Then, the researchers chose two students as participants in the study. These two students showed two different characteristics, even though their abilities in mathematics were at the same level.

\subsection{Error-Cognitive Conflict-Equilibrium - Solve the Problem}

The research process began with giving a story about distance material. S1 completed the problem by observing the researchers in the completion process, and the final results of the story questions given were analysed. The results of observations and analysis of the student's answer sheets were reinforced by indepth semi-structured interviews. S1 was chosen to be a participant because S1 has a wrong conception in solving the given problem. The results of the interviews between researchers and S1 are as follows:

Researcher: "Have you ever studied this material?

S1: "Yes, ever."

Researcher: "How do you solve the problem?"

S1: "When I read the question, I was confused about how to solve the problem. Then I reread and recalled how to solve the problem."

The statement from S1 shows the process of entering an external stimulus received via sensory memory, then transferring it to short-term memory. In terms of accessing information in the long-term memory, there were a few obstacles. S1 could not directly determine how the problem-solving process was given. S1 tried to re-enter the external stimulus by reading the question again. Finally, S1 could connect the information received in short-term memory with information that already existed in long-term memory. In this condition, S1 did not experience cognitive conflict. Then, the interview process continued as follows:

S1: "By using the calculation of reduction and addition operations. First, I subtract the distance between city A and city B. Then, I add the results to city C. The result is $3 \mathrm{~km} . "$

Researcher: "Why do you subtract city A and city B?"

S1: "Because the direction in the image of city A and city B is opposite. City A to the right and city B to the left."

Researcher: "How much is the difference between city A and city B?"

S1: “-14 km"

Researcher: "Do you know the distance from your house to school?"

S1: "Close. Only 1 km.” 
Researcher: "What about the distance from school to home?"

S1: "Same, $1 \mathrm{~km}$. "

Researcher: "What about the direction of the house to school and school to home, is it the same?"

S1: "Opposing"

Researcher: "If it's the opposite?"

S1: "Um . . . I'm confused. Negative period? The distance is the same. Means there is no negative distance."

Researcher: "What about the results in your answer?"

S1: "Yes, the results are negative. But the distance is not negative, um ..."

The interview shows that S1 experienced cognitive conflict after the researchers directed him to adjust his answer based on the definition of distance. Cognitive conflict occurs when information is entered in the short-term memory and students try to connect it with existing information in their long-term memory. The process of accessing information from long- memory in short-term memory occurred after the researchers repeated questions related to the definition of distance and then adjusted it to S1's solutions. Accessing the long-term memory takes quite a long time because it has not found a meeting point with the information that enters short-term memory. This access process is also carried out by alternating (short-term memory-long-term memory-short-term memory). So, for some time, S1 was still in cognitive conflict between the definition of distance and the results of his work. S1's process of working can be seen in the following figure:

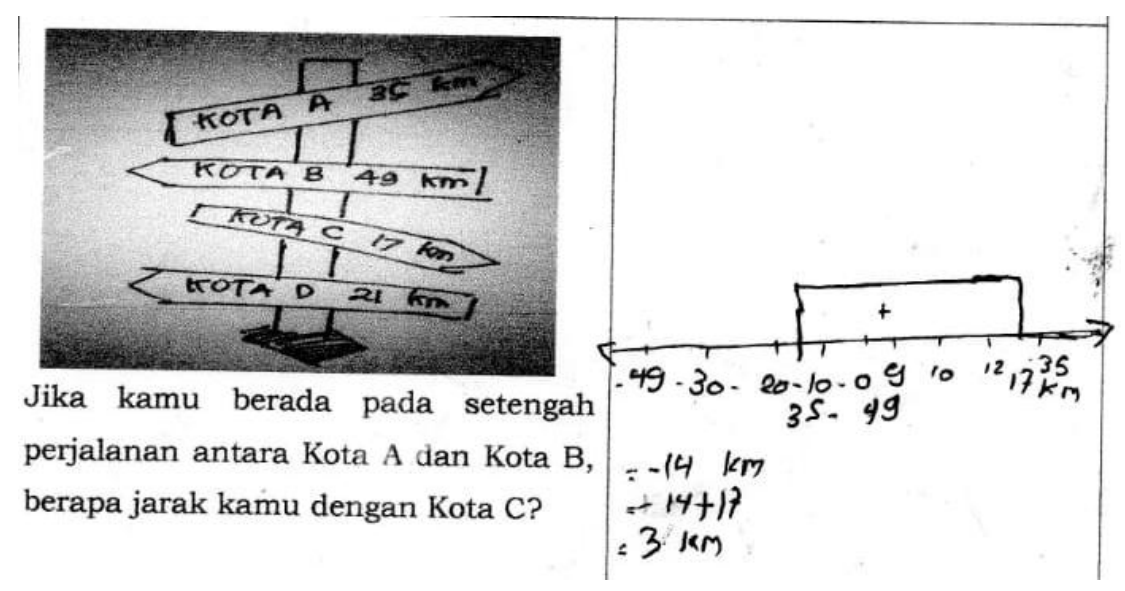

Figure 3. S1's Worksheet

Researcher: "Are you sure that your answer is correct?"

S1: "I'm not sure after knowing that there is no negative distance."

Researcher: "So what is the correct answer?"

S1: "It is true that city A and city B are in opposite directions. After I reread the question, I should look for the midpoint between city A and city B. If I search for the midpoint, then the distance of city A from the sign board and the distance of 
city B from the sign board are added up, then divided by two. The result is 42 $\mathrm{km}$. It means that my distance is only $7 \mathrm{~km}$ from the sign board; to go to city C, I only add $17 \mathrm{~km}$, so the result is $24 \mathrm{~km}$."

From S1's answer after trying to understand the question again and beginning to understand that there is no negative distance, an equilibrium process can be observed in his cognitive structure. After understanding the definition and looking at the results of his work, S1 realized where his mistakes were and tried to complete the questions given again. Finally, S1 found the correct solution. This condition shows that S1 could connect information that entered his shortterm memory with information in his long-term memory.

\subsection{Error-Cognitive Conflict-Equilibrium -Can't Solve the Problem}

Treatment of the research process with S2 was the same as with S1. S2 completed the story problems given, after which the researchers analysed his answers and then conducted a semi-structured in-depth interview with S2. S2 was chosen as a participant because he had a wrong conception in solving the given story problem. The results of interviews between the researchers and S2 are as follows:

Researcher: "Have you ever studied this material?

S2: "Yes, ever."

Researcher: "How did you solve the problem?"

S2: "First I read the question, then to facilitate the solution, I drew a line and gave a number."

Researcher: "What is the meaning of the line then given the number?"

S2: "The number line with the right and left directions is like the picture in the question."

S2's statement shows that he could understand the intent of the problem and remember the material that had been studied before. In processing information, an external stimulus is received by sensory memory and then transferred to short-term memory. In this stage, S2 did not experience difficulties when accessing information in long-term memory. So, the information received could be connected with the information that had been stored in long-term memory. In this condition, S2 did not experience cognitive conflict. So, the interview process continued as follows:

Researcher: "How did you solve this problem?"

S2: "I subtracted city A and city B. After I found the result, I added it to city C."

Researcher: "Why did you subtract city A and city B?"

S1: "Because in the picture in the question, the directions of city A and city B are opposite."

Researcher: "How much is the difference between city A and city B?"

S2: "-14 km"

Researcher: "How much is the distance from your house to school and from school to your home?"

S2: "Approximately $5 \mathrm{~km}$."

Researcher: "Where is the $5 \mathrm{~km}$ distance from?" 
S2: "Distance from home to school."

Researcher: "And the distance from school to home?"

S2: "5 km too."

Researcher: "How about the direction from home to school and school home?"

S2:" Opposite."

Researcher: "If it is the opposite, how is the distance?"

S2: "If the opposite, it is negative. But the distance from home to school and school to home is the same, $5 \mathrm{~km}$, there is nothing negative. So confused, um . . .

The interview above shows that S2 experienced cognitive conflict with the examples of distance given by the researchers. S2 sought to link the information received with existing information. This interview process repeated itself with examples of the same conditions. Information in S2's long-term memory said that there is no distance that is negative. However, when S2 looked at the problem-solving process, he found that the results of calculating the distance obtained were negative. S2 experiences cognitive conflict between definitions that exist in long-term memory and the results of their work. In this condition, the researchers tried to direct S2 to be able to connect the existing information. S2's problem-solving process can be seen in the following figure:

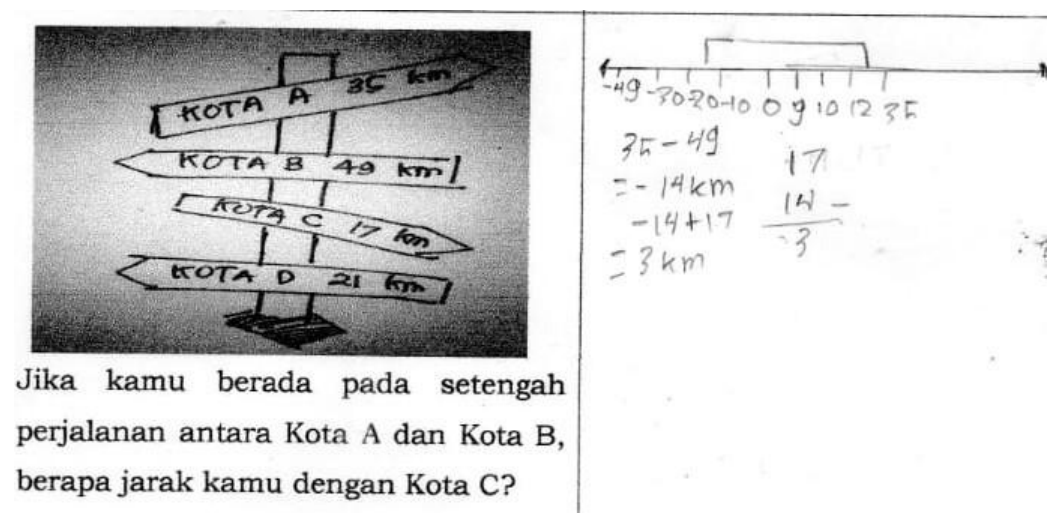

Figure 4. S2's Worksheet

S2 tried to understand the meaning of the distance between home and school and between school and home having the same distance: that no distance is negative. Information in his long-term memory had a conception of distance that cannot be negative, but in reality, S2 saw the problem-solving process was correct and was negative. The researchers tried to direct S2 to the correct solution. But in his thinking process, he could not find the right solution, even though S2 knew that distance could not be negative.

Researcher: "Look at the solution to your problem."

S2: "The results are negative, so I'm doing something wrong."

Researcher: "Can you finish this problem again?"

S2: (After trying to find a way to solve the given problem.) "I don't know how to solve this problem." 
Accessing needed information in long-term memory is quite a long process. The repeated questions given by the researchers could direct S2 to what he did wrong. S2 also carried out the access process back and forth (short-term memory-long-term memory - short-term memory and so forth). This condition indicates that S2 could connect information entering short-term memory with information that already existed in long- memory but could not find the correct solution to the problem.

\section{Discussion}

The two study participants had a different process of receiving external information or stimulus into short-term memory. At the beginning of the problem-solving process, in S1, information transferred by sensory memory to short-term memory could not be directly connected with information in the long-term memory. S1 performed repeated access to the long-term memory until finally he could determine how to solve the given problem. This shows that, in the end, S1 could connect information in long-term memory with information that had just been received in short-term memory. This process occurred with the help of the researchers. Meanwhile, S2 directly linked information transferred from sensory memory to short-term memory to information in longterm memory so that he could directly determine how the problem-solving process was given.

Both participants did not experience cognitive conflict during the problemsolving process because both participants could work the problem until they found the final result (although the end result was wrong). However, there was cognitive conflict when they saw the results of their work, which was realized after the interview process was conducted with questions directed at the definition of distance. The participants tried to connect the definition of distance to the process of solving the problem of the stories they were working on. With the process of the question being given repeatedly and accessing information to connect newly received information with information that had been around for quite a long time, finally the participants could find a link between that information. It turned out that they realized that there was an error in the completion process if it was connected with the definition of distance itself. In this condition, the participants tried to access information contained in their long-term memory. The process of accessing this information was done repeatedly, so in the short-term memory, there was a process of repetition of information to find information that was in accordance with what was in the long-term memory. With the help of the researchers, finally, the participants managed to connect the information received in their short-term memory with the information that already existed in their long-term memory. This is consistent with Wyrasti (2016) and Wyrasti et al. (2016), who described how cognitive conflict occurs in the structure of students' thinking. Wyrasti's research tells us that the presence of cognitive conflict arises from and is solved by the students themselves. So, cognitive conflict occurs according to the definition of Lee et al (2003), which defines cognitive conflict as a conflict between cognitive structures (i.e., organized structures of knowledge in the brain) and the environment (e.g., an experiment, a demonstration, peer opinions, books, or 
others), or conflicts between conceptions in cognitive structures. The difference is, S1 successfully found the correct solution to the given problem, while S2 could not solve the problem but realized what he had done wrong. So, the process that occurred in S1 was error-cognitive conflict-equilibrium-solve the problem, and in S2, experience an error-cognitive conflict-equilibrium process - can't solve the problem. The process experienced by S2 contradicts the findings of Wyrasti (2018), who said that students who experience construction analogy errors and experience anomalous situations will have a problem-solving process managing anomaly situations and then fixing construction analogy errors and finally successfully resolving the problem.

Cognitive conflict occurs in information processing at the stage of re-accessing the long-term memory to be connected or matched with information received in short-term memory, which is strongly influenced by time. This is consistent with what Lutz and Huitt (2013) stated, that the amount of information that can be stored and accessed again for a stimulus or event is also influenced by time. There are individuals who find it very easy to access information in long-term memory even though the information has been stored for a long time. This is influenced by the organization of information storage in long-term memory itself. The arrangement and organization of information occurs when learners process and store information. Learners' abilities change over time as a result of their maturation and experience (Lutz \& Huitt, 2003). Furthermore, when students are presented with information and asked to recall the information provided, younger students struggle, as they have not been trained to easily remember information. But when they enter school, they begin to develop or be taught various strategies. At first, students will only use this strategy when asked by others, but as students become more competent in their use and use it more often, they will more easily use the strategy spontaneously (Flavell et al., 2002). However, in the case of one of the participants in this study, information was accessed long enough to finally find the conception based on pre-existing information, but the participant was not able to find a solution to the problem given. This condition shows that having the same maturity and experience does not mean that children's structuring and organization of information will be the same. Besides, one of the most important differences between beginners and experts is the structure and organization of the specific knowledge possessed (Lutz \& Huitt, 2003). It would be interesting if further studies are conducted to find out why, after finding misconceptions, some students still cannot find the solution or complete the problem correctly, even though the condition of their cognitive structure is at equilibrium.

\section{Conclusion}

Cognitive conflict begins with students' misconceptions when solving problems. Based on the discussion above, there are two characteristics of students' cognitive conflict in solving problems, namely, error-cognitive conflictequilibrium - solving the problem and error-cognitive conflict-equilibriumcan't solve the problem. Therefore, cognitive conflict occurs in students during the process of accessing existing information in the long-term memory. The 
purpose of accessing information in long-term memory is to match or connect it with information transferred by sensory memory to short-term memory. However, this access sometimes faces obstacles or difficulties getting back. Students' difficulty accessing information in long-term memory to be connected with information received by short-term memory results in cognitive conflict. So, cognitive conflict occurs during information processing if the information received by sensory memory and transferred to short-term memory cannot be directly linked to information in long-term memory.

\section{References}

Atkinson, R., \& Shiffrin, R. (1968). Human memory: A Proposed System and Its Control Processes. In K. Spence \& J. Spence (Eds). The Psychology of Learning and Motivation. Princeton, NJ: Van Nostrand.

Chow, T. C., \& Treagust, D. (2013). An intervention study using cognitive conflict to foster conceptual change. Journal of Science and Mathematics Education in Southeast Asia, 36(1), 44-64.

Flavell, J., Miller, P., \& Miller, S. (2002). Cognitive development (4th ed.). Upper Saddle River, NJ: Prentice-Hall.

Kabaca, T., Karadag, Z., \& Aktumen, M. (2011). Misconception, cognitive conflict and conceptual changes in geometry: a case study with pre-service teachers. Mevlana International Journal of Education (MIJE), 1(2), 44-55.

Lee, G. \& Kwon, J. (2001). What Do You Know About Students' Cognitive Conflict: A Theoretical Model of Cognitive Conflict Process. Proceedings of 2001 AETS Annual meeting, Costa Mesa, CA, pp. 309-325. (ERIC Document Reproduction Service No. ED 453083).

Lee, G., Kwon, J., Park, S-S., Kim, J-W., Kwon, H-HG., \& Park, H-K. (2003). Development of an Instrument for Measuring Cognitive Conflict in Secondary-Level Science Classes. Journal of Research in Science Teaching. Vol 40, No.6. pp: 585-603. Doi: https://doi.org/10.1002/tea.10099.

Limón, M. (2001). On the cognitive conflict as an instructional strategy for conceptual change: A critical appraisal. Learning and instruction, 11(4-5), 357-380. Doi: https://doi.org/10.1016/S0959-4752(00)00037-2.

Lutz, S., \& Huitt, W. (2003). Information Processing and Memory: Theory and Applications. Educational Psychology Interactive. Valdosta, GA: Valdosta State University.

Maharani, I. P., \& Subanji, S. (2018). Scaffolding Based on Cognitive Conflict in Correcting the Students' Algebra Errors. IEJME-Mathematics Education.

Meissner, H. (1986). Cognitive Conflicts in Mathematics Learning. European Journal of Psychology of Education, Vol 1, No.2, pp. 7 - 15. Doi: https://doi.org/10.1007/BF03172566.

Movshovitz-Hadar, N., \& Hadass, R. (1990). Preservice education of math teachers using paradoxes. Educational Studies in Mathematics, 21(3), 265-287. Doi: https://doi.org/10.1007/BF00305093.

Robert E.S. (2000). Educational Psychology: Theory and Practice. Pearson Education. New Jersey.

Schunk, D.H. (2012). Learning Theories: An Educational Perspectives, 6th Edition. New York: Pearson Education Inc.

Tall, D. (1977). Cognitive Conflict and the Learning of Mathematics. Paper presented at the First Conference of The International Group for the Psychology of Mathematics Education. Utrecht, Netherlands. 
Tirosh, D., \& Graeber, A. O. (1990). Evoking cognitive conflict to explore preservice teachers' thinking about division. Journal for Research in Mathematics Education, 98-108. Doi: 10.2307/749137.

Wyrasti, A. F. (2016). Penelusuran Konflik Kognitif Siswa dalam Menyelesaikan Masalah Matematika. In Prosiding Seminar Nasional Pendidik dan Pengembang Pendidikan Indonesia yang Diselenggarakan oleh APPPI, Dinas Pendidikan Kota Batu, dan PGRI Kota Batu pada 21 Mei 2016 di Kota Batu, Jawa Timur (Vol. 1, pp. 73-80). [Cognitive Conflict Search for Students in Resolving Mathematical Problems. In Proceedings of the National Seminar on Indonesian Education Educators and Developers Organized by APPPI, Batu City Education Office, and PGRI Batu City on May 21, 2016 in Batu City, East Java (Vol. 1, pp.73-80)]

Wyrasti, A. F., Sa'dijah, C., \& Anwar, L. (2016). The Assessment of Students' Cognitive Conflict by Using Student's Cognitive Map in Solving Mathematics Problem, (2006), In Proceeding International Conference on Education.72-82. ISBN: 978602-71836-1-2 ice/article/view/15.

http:// pasca.um.ac.id/conferences/index.php/

Wyrasti, A. F., Sa'dijah, C., As'ari, A. R., \& Sulandra, I. M. (2018). The Misanalogical Construction of Undergraduate Students in Solving Cognitive Conflict Identification Task. International Electronic Journal of Mathematics Education, 14(1), 33-47. 